\title{
Artificial intelligence, capsule endoscopy, databases, and the Sword of Damocles
}

We read with interest the editorial by Hassan et al [1] entitled "Al everywhere in endoscopy, not only for detection and characterization," prompted by the recent paper of Hansen et al. on "Novel artificial intelligence (AI)-driven software significantly shortens the time required for annotation in computer vision projects" [2]. As Hassan et al. point out, unlike classic machine learning methods (MLM), the new kid on the block's (i.e., deep learning [DL]) main advantage is its capability to automatically extract image features so that computers can use them to characterize their content [3]. This, essentially, means that the accuracy of this unsupervised approach depends primarily on the aptness and quality of the training data provided.

Especially in the field of capsule endoscopy (CE), where imaging data are readily available, it remains to be determined who will plough through the images, delineate/annotate and comment on regions of interest, and make sure that DL training is performed with highquality material. Considering this, putting in a substantial amount of human effort (including personal) [1], we set off to create a series of respective CE databases, i.e., KID, CAD-CAP, and Kvasir Capsule [4-6] for the benefit of computer scientists, at the expense of effort by ourselves and colleagues. Although they are enriched by and enlarged with CE images from different manufacturers, the diverse databases contain numerous classes of gastrointestinal normal and abnormal findings that have been prepared in various way. Therefore, the level of cleanliness in the databases is diverse and they offer a unique opportunity and respective point of reference for $\mathrm{Al}$ software developers. This approach sets the scene for structured delivery of a series of much-needed solutions for accurate detection and characterization of abnormal CE findings. These include reliably producing thumbnails of anatomical landmarks (i.e. stomach, small bowel, colon), which is of tremendous importance especially with the emerging trend of panenteric CE [7]; reproducible assessment of bowel cleanliness [8], which can easily surpass that of human readers [9], thus allowing crucial decisions to be made on repeating a procedure; and, crucially, the relevance of findings according to the clinical setting [10].

The experience to date shows that the time required to create such databases is substantial, and the overall effort, cleverly described as human slavery to the inanimate Al master [1], is far from negligible. Instinctively one would want to consider maximizing the use of all the existing databases. However, planning for the future, we need concrete standards/guidelines for creating new databases according to user needs and international General Data Protection Regulation requirements. At present, though, our Sword of Damocles is sorting out any related medico-legal issues about data protection and eventually merging all the databases into a unique, free-toaccess, single database for DL training in CE [11].

\section{Competing interests}

Dr. Dray is co-founder of and a shareholder in Augmented Endoscopy and has received lecture fees from Bouchara Recordati, Fujifilm, Medtronic, MSD, and Pfizer and has acted as a consultant for Alfasigma, Boston Scientific, Norgine, and Pentax. Dr. Toth has received consultancy/lecture fees from Medtronic. Dr. de Lange is Medical Chief Scientist and a shareholder in Augere Medical, an Al startup. Dr. Koulaouzidis is a consultant for Jinshan, director of iCERV Ltd and cofounder of AJM Medicaps Ltd and has received a Givenlmaging Ltd-ESGE grant and material support for clinical research from SynMed/Intromedic. In the last 10 years, he has received honoraria and lecture fees from Jinshan, Dr FalkPharma UK, and Ferring. He has also received educational travel support from Aquilant, Jinshan, Dr FalkPharma UK, Almirall, Ferring, and has participated in advisory board meetings for Tillots, Ankon, and Dr FalkPharma UK.

The authors

Xavier Dray ${ }^{1}$, Ervin Toth ${ }^{2}$, Thomas de Lange ${ }^{3}$, Anastasio Koulaouzidis ${ }^{4}$

1 Sorbonne University, Centre for Digestive Endoscopy, Hôpital Saint Antoine, APHP, Paris, France

2 Skane University Hospitals, Endoscopy Unit, Department of Gastroenterology, Malmo, Sweden

3 Sahlgrenska University Hospital-Molndal, Medical Department, Gothenburg, Sweden

4 Pomeranian Medical University in Szczecin, Department of Social Medicine \& Public Health, Faculty of Health Sciences, Zchodniopomorskie, Poland

\section{Corresponding author}

\section{Anastasios Koulaouzidis}

Pomeranian Medical University in Szczecin, Department of Social Medicine \& PublicHealth, Faculty of Health Sciences, Zchodniopomorskie, Poland akoulaouzidis@hotmail.com

\section{References}

[1] Hassan C, Mori Y, Antonelli G. Al everywhere in endoscopy, not only for detection and characterization. Endosc Int Open 2021; 9: E627-E628

[2] Hansen US, Landau E, Patel M et al. Novel artificial intelligence-driven software significantly shortens the time required for annotation in computer vision projects. Endosc Int Open 2021; 9: E621-E626

[3] Dray X, lakovidis D, Houdeville C et al. Artificial intelligence in small bowel capsule endoscopy - current status, challenges and future promise. J Gastroenterol Hepatol 2021; 36: 12-19

[4] Koulaouzidis A, lakovidis DK, Yung DE et al. KID Project: an internet-based digital video atlas of capsule endoscopy for research 
purposes. Endosc Int Open 2017; 5: E477E483

[5] Leenhardt R, Li C, Le Mouel JP et al. CADCAP: a 25,000-image database serving the development of artificial intelligence for capsule endoscopy. Endosc Int Open 2020; 8: E415-E420

[6] Smedsrud PH, Thambawita V, Hicks SA et al. Kvasir-Capsule, a video capsule endoscopy dataset. Scientific Data 2021; 8: 142 https://www.nature.com/articles/s41597021-00920-z

[7] Dray X, Koulaouzidis A. Panenteric capsule endoscopy; a new soldier at the forefront of lower gastrointestinal bleeding workup and...beyond! Eur ] Gastroenterol Hepatol 2021: doi:10.1097/MEG.000000000000 2085
[8] Dray X, Houist G, Le Mouel JP et al. Prospective evaluation of third-generation small bowel capsule endoscopy videos by independent readers demonstrates poor reproducibility of cleanliness classifications. Clin Res Hepatol Gastroenterol 2021; 45: 101612

[9] Leenhardt R, Souchaud M, Houist G et al. A neural network-based algorithm for assessing the cleanliness of small bowel during capsule endoscopy. Endoscopy 2020: doi:10.1055/a-1301-3841

[10] Leenhardt R, Koulaouzidis A, McNamara D et al. A guide for assessing the clinical relevance of findings in small bowel capsule endoscopy: analysis of 8064 answers of international experts to an illustrated script questionnaire. Clin Res Hepatol Gastroenterol 2021; 45: 101637
[11] Koulaouzidis A, Toth E. Image database, AI and capsule endoscopy; the bets are on. Endosc Int Open 2020; 8: E421-E422

\section{Bibliography}

Endosc Int Open 2021; 09: E1754-E1755

DOI 10.1055/a-1521-4882

ISSN 2364-3722

(c) 2021. The Author(s).

This is an open access article published by Thieme under the terms of the Creative Commons Attribution-NonDerivativeNonCommercial License, permitting copying and reproduction so long as the original work is given appropriate credit. Contents may not be used for commercial purposes, or adapted, remixed, transformed or built upon. (https:// creativecommons.org/licenses/by-nc-nd/4.0/)

Georg Thieme Verlag KG, Rüdigerstraße 14, 70469 Stuttgart, Germany 